\title{
O TRABALHO DE ENFERMAGEM E SUA ARTICULAÇÃO COM O PROCESSO DE TRABALHO EM SAÚDE COLETIVA REDE BÁSICA DE SAÚdE EM RIBEIRÃO PRETO *
}

\author{
Maria Cecflia Puntel de Almeida ** \\ Débora Falleiros de Mello *** \\ Lis Aparecida de Souza Neves ****
}

RESUMO - O objeto central desta pesquisa é o estudo da organização tecnológica do trabalho de enfermagem na Rede Básica de Serviços de Saúde de Ribeirão Preto. O objetivo é caracterizar o trabalho de enfermagem e sua articulação com o conjunto dos trabalhos nas Unidades Básicas de Saúde (UBS), bem como identificar a que finalidade o trabalho está atendendo. Através de observação direta dos setores do serviço, e de entrevistas com os profissionais, foram caracterizados os momentos do trabalho em saúde. Foram selecionadas 3 UBS e estas observadas durante 3 meses consecutivos, nos setores de: recepção da clientela, pré-consulta, consulta-médica, vacinação, suplementação alimentar, aplicações de tratamento e o trabalho da enfermeira. Conclui-se que as atividades estão voltadas para a consulta médica, enquanto atendimento individual e a enfermagem está inserida neste processo de trabalho, desenvolvendo atividades auxiliares da consulta. 0 modelo de saúde predominante é o Pronto-Atendimento, sem desenvolvimento de ações de Saúde Coletiva.

\begin{abstract}
The central topic of the present research is the study of the technological organization of nursing work in the Basic Network of Health Services of Ribeirão Preto. The objective has been to characterize nursing work and its articulation which the services provided at Basic Health (BHUs) and to identify the purposes that are fulfilled by this work. The moments of health work have been characterized by direct observation of the service sectors and by interviewing the professionals involved. Three BHUs have been selected and observed over a period of 3 consecutive months in the sectors of: client reception, pre-visit, medical visit, after-visit, vaccination, feeding supplementation, application of treatment and nursing work. It has been concluded that the activities are directed at the medical visit as individual care, and the nurse is involved in this working process by performing activities that complement the medical visit. The predominant health model is First Aid, with no development of collective health actions.
\end{abstract}

\section{O OB JETO EM ESTUDO E A FUNDAMENTAÇĀO TEÓRICA E METODOLÓGICA}

O mais freqüente é considerar a enfermagem como uma profissão, portanto com um es-. tatuto socialmente reconhecido e formalmente legalizado. E sendo uma profissão deve constituir-se dos critérios de universalidade, racionalidade, autoridade e competência no seu campo específico. Em relação à competência profissional, os livros textos consideram que a função peculiar da enfermeira é prestar assistência de enfermagem ao indivíduo doente ou sadio, família ou comunidade, no desempenho de atividades para prevenir a doença, manter ou recuperar a saúde.

A aproximação que vamos fazer da enfermagem a considera além de uma profissão com sua competência técnico-científica, a apreende como uma prática social e assim sendo como trabalho e no próprio desenrolar deste, ou seja,

*Frêmio Isaura Barbosa Lima - 1ํ lugar - 43ำ Congresso Brasileiro de Enfermagem - Curitiba-PR - 1991 - trabalho extraído da Tese de Livre-Docência de Maria Cecília Puntel de Almeida, Escola de Enfermagem de Ribeirāo Preto - USP, março de 1991.

** Professor Associado do departamento de Enfermagem Materno-Infantil e Saúde Pública - EERP-USP.

*** Enfermeira da Secretaria Municipal de Saúde de Ribeirão Preto e Pós-Graduando - Nível Mestrado em Enfermagem Fundamental do Departamento de Enfermagem Geral e Especializada - EEKP-USP.

**** Enfermeira da Secretaria Municipal de Saúde de Ribeirão Preto. 
no processo de trabalho da saúde, pretende-se identificar seus momentos caracterizando sua finalidade, tecnologia, objeto e agentes, nas possibilidades e espaços dados pelo próprio desenrolar do trabalho.

Já se tem um volume científico razoável em enfermagem enquanto prática social e, numa análise sumária e provisória do realizado até agora, pode-se dizer que esta produção possibilitou macro-análises da enfermagem na formação social capitalista e em especial sua gênese e evolução histórica na sociedade brasileira, traçando um pano de fundo para compreensão de sua dimensão histórica e social. Nesta avaliação percebe-se a necessidade de continuar trilhando este caminho mas agora aprofundando e especificando mais as análises, na tentativa de compreender melhor as razões deste trabalho e sua articulação com o setor saúde nos micro-espaços institucionais concretos e nas especialidades desta prática. Assim tem-se como referencial teórico e metodológico o modelo de organizaçāo tecnológica do trabalho, desenvolvido por MENDES - GONÇALVES ${ }^{3}$. Este modelo fundamenta-se no processo de trabalho segundo o referencial de MARX, entendendo "não apenas os instrumentos materiais, mas também saber enquanto forma variável e contrariamente adequada de organizar "internarnente" certas práticas referidas à saúde e à doença, ao mesmo tempo em que forma variável e contraditoriamente adequada de suportar a articulação dessas práticas na totalidade social histórica"..3.

As necessidades ou os carecimentos dos homens não são de um homem só, pois este vive, sofre e trabalha com os outros homens, e assim não são naturais. São carências sociais que tomadas como finalidades para presidir o processo do trabalho, satisfazando-as. A geração como a satisfação destes carecimentos. Portanto a geração bem como a satisfação das necessidades através do trabalho é um processo social e ao mesmo tempo histórico, porque nele se dá a produção e reprodução deste homem que é social. Os agentes do trabalho de enfermagem, bem como aqueles portadores de necessidades de saúde se relacionam com outros homens, através de seus produtos, na divisão social do trabalho. Não é portanto um processo natural, bom ou mau, $e$ necessariamente social e histórico. Em outras palavras, recorremos aos dizeres de MENDES - GONÇALVES": "dadas as características do trabalho humano, por produzir sempre face às necessidades sociais, por relacionar os homens através de seus produtos, por relacioná-los conforme o grau de domínio que têm (ou deixam de ter) das condições de trabalho, o processo de trabalho humano é antes de tudo o mais o processo de produção e reprodução do homem social, historicamente determi- nado, através da prodnçă de bens e serviços"

Já se tem amplo conhocimento da gênese da enfermagem atividade tal como é conhecida e produzida na atualidade. $O$ conhecimento médico clínico tem sua origem no final do século XVIII, no mesmo movimento social de transformação do hospital enquanto local de cura. No século XIX, na Inglaterra, surge a enfermagem como uma prática que possibilita a tomada do corpo doente como objeto do trabalho médico, higieniza e disciplina o espaço hospitalar num projeto de recuperação individual. A partir dar a clínica vai instrumentalizando o saber anátomo-patológico para recortar o seu objeto de trabalho e apreendê-lo, ou seja o corpo doente, a doença. Este é o modelo clínico que tem por finalidade a recuperação do corpo individual. $\mathrm{E}$ o agente que, histórica e socialmente preside este processo é o médico. Ele, através dos meios de trabalho e o saber da clínica, permite manipular, conhecer e restaurar o objeto de trabalho médico - o corpo - a fim de atender esta finalidade, produzindo a recuperação. Para possibilitar a realização do modelo clínico e, com a complexidade do conhecimento e da infra-estrutura institucional (no caso o hospital e outros instrumentos necessários), outros trabalhadores vão se agregando a este trabalho, o qual passa a ser um trabalho coletivo. Como no trabalho em geral a concepção se separa do momento da execução (em agentes e tempos que podem ser diferentes), também na saúde haverá esta divisão nos momentos mais intelectuais e mais manuais do trabalho. Caberá ao médico a apropriação do momento mais intelectual do trabalho (diagnóstico e terapêutica) e assim será o agente hegemônico deste processo.

A enfermagem, portanto, neste modelo clínico de saúde é parte deste processo e do trabalho médico, sua ação $\varepsilon$ um instrumento de trabalho médico que "cuidará" ou "fará cuidar" do corpo doente. A observaçãò de enfermagem, o levantamento de dados, o planejamento, a evolução, a avaliação dos pacientes, os sistemas de assistência, os procedimentos técnicos e de comunicação e integração entre pacientes e enfermagem e entre os diversos profissionais são, entre outros, alguns dos instrumentos de trabalho deste processo "cuidar". Do mesmo modo que o objeto, a finalidade deste processo "cuidar" è a mesma finalidade do trabalho médico, isto e "curar corpos individuais" .

Além da ação de "cuidar" no modelo clínico, outro tipo de atividade, também resultado histórico e social é o "administrar" e que não é realizado por todas as categorias de enfermagem mas sim pela enfermeira. Os -instrumentos utilizados entre outros são: os próprios modelos e métodos de administração, normas e rotinas, a força de trabalho em enfermagem (os auxilia- 
res), os equipamentos e materiais permanentes e aqueles para a manipulação e administração de drogas e soluções.

Não só o modelo clínico emerge com o capitalismo para dar conta das necessidades de saúde próprias das sociedades capitalistas, emerge tamberm, a outra vertente, o modelo de saúde coletivo. Aqui a concepção da doença não é fenômeno individual centrado no corpo do doente, mas doença com fenômeno coletivo, tendo a epidemiologia por um dos pressupostos fundamentais.

Estes dois modelos que estão sendo tomados na sua forma abstrata não são excludentes, são dimensões de uma mesma realidade, a saúde, que é dinâmina e contraditória.

Como a enfermagem é uma parcela do trabalho em saúde, ela tamberm vai estar presente na produção de serviços de saúde a nível coletivo. Será também um instrumento de trabalho, mas agora não mais do trabalho médico, mas um dos instrumentos para alcançar a saúde.coletiva. E assim o trabalho de enfermagem tem se diversificado indo desde o "cuidar" de enfermagem até a participação no planejamento em saúde.

Como nosso objeto de investigação é o trabalho de enfermagem a nível de saúde coletiva, e para conhecê-lo e analisá-lo em uma dada concreticidade, vamos tomar o seu saber e verificar como este se expressa na produção de serviços de saúde e as relações sociais que seus agentes estabelecem neste processo de trabalho. Assim sendo, temos como objetivo central deste estudo caracterizar o trabalho da enfermagem na Rede Básica de Serviços Públicos de Saúde de Ribeirão Preto, estabelecendo suas articulações com autras ações em saúde, e desta forma entendendo suas finalidades coletivas.

\section{O TRABALHO DE CAMPO}

O trabalho de campo foi realizado em Unidades Básicas de Saúde (UBS) * da Secretaria Municipal de Saúde (SMS) ** - Ribeirão Preto 7. Das 23 UBS foram sorteadas 3 UBS, segundo os critérios de maior demanda de clientes, as que desenvolviam as ações básicas estabelecidas pela SMS - atendimento em pediatria, ginecologia-obstetrícia, clínica médica, programa de suplementação alimentar e vacinação - e que não fossem de nível distrital e nem local de trabalho dos auxiliares de pesquisa. Foram denominados como UBS-A, UBS-B e UBS-C. Os instrumentos de pesquisas utilizados foram a observação sistemática direta do trabalho, constituindo-se o instrumento central da coleta de dados empíricos, e as entrevistas, que tinham a finalidade de complementar as observações, e

(*) UBS = Unidade Básica de Saúde

(**) SMS = Secretaria Municipal de Saúde através delas captar a fala dos trabalhadores de saúde sobre o que estão fazendo, ou seja, a representação que têm sobre o seu trabalho. Foram entrevistados todos os trabalhadores das 3 UBS que correspondeu a 37 entrevistas. Todo o trabalho de campo teve a duração de três meses (fevereiro, março e abril de 1990).

\section{III - OS MOMENTOS DO PROCESSO DE TRABALHO NAS UNIDADES DE SAÚDE - RIBEIRÃO PRETO}

\section{O objeto de trabalho - os clientes}

Foram registrados, durante os 3 períodos de observação, o número de clientes que procurou atendimento clínico, a faixa etária dos mesmos, ou seja, < 1 ano, 1 a 4 anos, 5 a 14 anos e 15 e mais, bem como a especialidade médica dos atendimentos. Também foi registrada a demanda que compareceu e por falta de vaga não foi atendida, que se denomina demanda reprimida.

Analisando-se os dados da demanda atendida em relação à reprimida, verificou-se que 378 clientes foram atendidos e 175 não foram, o que corresponde a aproximadamente à metade da demanda atendida. Este número registrado de demanda reprimida $\varepsilon$ bem maior, pois um grande número de clientes que fica na fila, e quando a funcionária fala que já não há vagas, estes saem, vão embora sem chegar a se apresentar na recepção. As maiores demandas reprimidas são as de adultos e mulheres (ginecologia).

Além de não haver nenhum atendimento do tipo de ação programática em saúde, o próprio atendimento clínico realizado nas UBS não tem uma organização tecnológica que permita uma identificação e evolução mais precisa e detalhada da clientela, nem em termos anátomo-funcionais e muito menos sociais.

O seguimento do cliente depende da necessidade que o médico estabelece para que o mesmo volte e nem sempre o retorno é aprazado, ficando para o cliente estabelecer de acordo com sua necessidade. Portanto o modelo assistencial pode ser caracterizado como "ProntoAtendimento".

As ações de enfermagem na recepção que atendem a este modelo, são ações de controle e repressão da demanda. Os médicos não comparecem neste setor, não entram em contato diretamente com a pressão que a população faz para receber consulta médica.

No que se refere à compreensão dos funcionários sobre o trabalho que realizam no fichário, se relaciona mais à importância do prontuário do cliente em termos de seu acompanhamento individual do que à possibilidade de co- 
meçar a conhecer a clientela que demanda para aquele serviço.

Uma questão que colocamos é que, mesmo todos os trabalhadores representando o processo saúde-doença como condições de vida, no momento em que estes clientes procuram a consulta médica, os médicos fazem uma abstração dessas pessoas concretas e tomam como objeto o problema-queixa como será analisado no padrão das consultas do trabalho do médico. $\mathrm{E}$ isto é compreensível, uma vez que o saber médico que circunscreve o modelo clínico, é o conhecimento da doença e os padrões de normalidade já pré-estabelecidos pela medicina. Este saber começa e termina no recorte do corpo anátomo-fisiológico. A proposta de modelo integral de assistência preconizada pela SMS, se for realizado só cọm o instrumento de trabalho, a consulta médica eventual, fica longe de atingir esta integralidàde.

Outro aspecto importante a ser discutido sobre a concepção dos trabalhadores em relação à característica da população de abrangência da UBS e as relações com o trabalho dos mesmos, são as concepções de "exterioridade" que estes concebem à população. Este grupo de trabalhadores que diz que as características da população não interferem no seu trabalho, concebe a população como "externa" ao seu trabalho, que é tomado como sendo técnico e a saúde neste caso não é vista como condição de vida, mas somente como uma disfunção anátomo-fisiológica. Somente uma enfermeira considera as características da população como "internas" ao seu trabalho e como objeto a ser recortado e trabalhado no seu cotidiano.

Com relação à satisfação das necessidades de saúde da população pelas UBS, dos 37 entrevistados, 12 pensam que a UBS satisfaz as necessidades pelo fato de atender à população e este trabalho se relaciona às especialidades médicas, como ginecologia, clínica médica e pediatria, e ao fato de fornecer medicação. Os outros 25 entrevistados pensam que não satisfaz as necessidades da população devido a três problemas. Em primeiro lugar apontam a falta de medicamentos, exames laboratoriais, médicos e infra-estrutura física. Em segundo lugar vem a demanda reprimida que é grande e, em terceiro apontam as condições de probreza da população que dificultam o atendimento, a compra de medicação e a mudança para hábitos sadios. Somente uma enfermeira apontou "a falta de motivação do pessoal para atingir a proposta de reestruturação da saúde", como fator relevante.

O padrão de representação dos trabalhadores da saúde, em termos dos resultados da produção de serviços de saúde, continua sendo o mesmo, já apontado, em momentos anteriores, ou seja, a produção de serviços de saúde se refere centralmente à consulta médica, exames la- boratoriais e medicações. A demanda que não drena espontaneamente para os serviços, que é a demanda potencial, não é objeto de trabalho nem na representação dos trabalhadores.

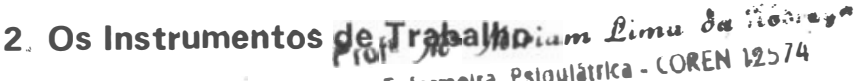 2.1 As pré-consultas Entermelra Mat. UFPB-6593}

A pré-consulta é realizada da seguinte maneira: os prontuários ficam na escrivaninha em ordem numérica, colocados em ordem de chegada na recepção. Uma auxiliar de enfermagem chama um grupo de clientes, em torno de 3 a 4. Enquanto uma ou duas auxiliares vão verificando peso e estatura, a outra funcionária vai registrando na folha de evolução dos prontuários.

O diálogo mantido entre auxiliares e mães é bastante rápido, e se refere à queixa que estas trazem sobre o estado de saúde da criança e as mesmas não são registradas no prontuário. $\mathrm{O}$ tempo gasto nesta atividade de pré-consulta correspondeu em média a 1 minuto e meio para cada cliente nas três UBS. A preocupação central é registrar os pesos e as medidas dos clientes.

A pergunta feita em relação à pré-consulta foi "qual o caminho percorrido pelo cliente nesta UBS e porque passa em cada um destes setores". A resposta quase unânime de todas as categorias profissionais relaciona a pré-consulta à mensuração. Um grande número de trabalhadores expressou que esta mensuração se refere a pesar e medir os clientes. Além disso a preocupação com a avaliação do estado de saúde do cliente que requer um "pronto atendimento", como abaixar a temperatura e a pressão arterial, há um pequeno número de trabalhadores que se refere à pré-consulta como um dos momentos de fazer orientações educativas e de conhecer melhor a clientela. Este pequeno número de trabalhadores tem uma visão mais ampliada da préconsulta no sentido da educação em saúde e do conhecimento do cliente, não somente em relação às suas queixas mas enquanto um ser social. Reconhecem também que este tipo de atendimento que estão realizando divide muito o cliente.

A pré e pós-consulta bem como o atendimento de enfermagem foram atividades de enfermagem formalizadas no estado de São Paulo, por ocasião das ações programáticas em saúde da Secretaria de Estado, na década de 70. Eram ações pertinentes às programações em saúde que tinham a finalidade de controlar a doença a nível coletivo.

A pré, a pós-consulta e o atendimento de enfermagem foram consideradas como atividades-parte das ações programáticas em saúde que não visavam exclusivamente o atendimento clínico. 


\subsection{0 trabalho do Médico - As Consultas Médicas}

Dos 10 médicos entrevistados das 3 UBS observou-se o trabalho de 9 , sendo 4 pediatras, 2 ginecologistas e 3 clínicos. Como o trabalho médico se restringe, quase na sua totalidade à consulta médica, esta foi a atividade observada.

As observações corresponderam a um turno de trabalho dos 9 médicos, o que resultou no atendimento de 128 consultas, sendo 58 de pediatria, 43 de clínica e 27 de ginecologia. O tempo de jornada diária contratada dos médicos, por turno de trabalho, corresponde a 4 horas ou 240 minutos. Dos 9 médicos corresponderam a 1160 minutos de tempo de jornada contratada, sendo que destes foram trabalhados, 1439 minutos e 721 minutos não trabalhados, o que correspondeu a uma percentagem de $33,37 \%$ de tempo não trabalhado. $U$ tempo médio dispendido em cada consulta correspondeu de $10 \mathrm{~min}$, e $2 \mathrm{~s}$ e o número médio de consultas por médico foi de 14,22 consúltas por 4 horas de trabalho.

Observando-se o tempo de cada consulta há uma variação, sendo que há médicos que dispendem uma média de 6 min e $52 \mathrm{~s}$ e outros 13 min e $44 \mathrm{~s}$, correspondendo a uma média das médias para todos os médicos de $10 \mathrm{~min}$ e $22 \mathrm{~s}$ por consulta. Portanto o tempo de 15 minutos estipulado para se fazer uma consulta médica não foi todo utilizado nas consultas.

Analisando-se as consultas segundo o modelo tecnológico observou-se que as mesmas seguem um padrão, tanto em relação aos casos novos como aos retornos, ou seja: as consultas começam com o médico perguntando ao próprio cliente ou aos responsáveis (mãe) o que está sentindo, ou o que o trouxe ao médico. O diálogo compreende perguntas e respostas monossilábicas e centradas na queixa que conduzem ao diagnóstico. Não se observa a realização de uma história de cada cliente.

Esta consulta não corresponde nem ao modelo clínico; o objeto de trabalho é a doença e não o doente. $O$ instrumento de trabalho médico é agora a queixa, não como um primeiro momento da relação médico-paciente para desembocar na história, exame físico, hipótese diagnostica e conduta, mas como momento central da consulta. Este padrão de consulta médica já foi observado e analisado por MENDES GONÇALVES $^{3}$ na Rede Estadual de Centros de Saúde da cidade de São Paulo.

A articulação do trabalho do médico (que é a consulta) com os outros trabalhos na UBS se dá exatamente em função da medicação prescrita e encaminhamento para os exames solicitados e esta articulação se dá com a atividade de pós-consulta que é realizada pelas auxiliares de enfermagem.
Ourro dado importante é o fato dos diagnósticos das consultas médicas não serem registrados enquanto um dado para compor o perfil de morbidade da demanda atendida. Este perfil epidemiológico da demanda atendida seria o primeiro momento do processo de trabalho para a organização da assistência em saúde no modelo epidemiológico, a fim de atingir também a demanda potencial com a finalidade de controlar a doença a nível da população.

Nas entrevistas quando lhes perguntamos “quais são suas atividades de rotina e se poderiam descrevê-las em relação ao modo de realização, horário, conteúdo e finalidade", todos responderam que são as consultas. Como não há uma política de saúde no direcionamento da saúde coletiva, não há como dar uma outra finalidade à consulta médica que não a de se resolver os aspectos curativos individuais de cada cliente; a finalidade termina na própria consulta. Os outros procedimentos de saúde coletiva, como vigilância epidemiológica, sanitária, educação, vacinação e outros, não são apontados como passíveis de serem instrumentos de trabalho das UBS.

Quando pedidos que "fizessem uma avaliaçāo do seu trabalho na UBS, em termos da finalidade do mesmo", um grupo (a metade) acha que é satisfatória pois a "resolutividade é boa" e esta é referida à eficácia da consulta. $O$ conceito da resolutividade expresso está centrado na qualidade da consulta e na experiência clínica. Não aponta para outras categorias do processo saúde-doenç̧a além daquelas que são detectadas na funcionalidade do corpo biológico.

Ao mesmo tempo que há alguns médicos que têm a visão que saúde-doença não é só um processo anátomo-fisiológico, outros relacionam a conscientização da população à execução das ordens medicamentosas prescritas.

Mesmo a representação que fazem sobre a consulta do ponto de vista da medicina preventiva individual, esta não correspondeu a procedimentos realizados nas consultas observadas. Foram pouquíssimas as ações educativas realizadas nas consultas médicas envolvendo a promoção e prevenção da saúde, mesmo visando a individualidade de cada cliente, e quando ocorreram foram de natureza autoritária.

\subsection{As Pós-consultas}

Todos os clientes que passam por consulta médica são atendidos na pós-consulta, não há separação entre as áreas de pediatrià, clínica e ginecologia-obstétricia. Os clientes após a consulta levam o prontuário para a sala de pós-consulta formando uma fila para o atendimento. A sala fica aberta e são atendidos também em grupos de dois ou três como na pré-consulta. 
De um modo geral a atividade de pós-consulta se constitui em ler ligeiramente o que foi registrado pelo médico. Quando há pedidos de exames laboratoriais, orienta-se como fazer a coleta e os dias e horários da mesma. Os registros da pós-consulta no prontuário do cliente são bastante sucintos, não se referem ao conteúdo das orientação feitas. Em uma UBS não se registra nenhum dado da pós-consulta no prontuário.

O tempo de atendimento de 30 clientes correspondeu a 67 minutos, ou seja, em cada orientação foi gasto 2 minutos e 14 segundos. Torna-se difícil neste curto espaço de tempo fazer orientação de caráter educativo. As atividades de prevenção e promoção da saúde foram praticamente inexistentes, e quando ocorreram se referiram ao encaminhamento para vacinação e algumas orientações individuais de higiene e alimentação infantil.

Analisando a representação que os trabalhadores têm sobre a pós-consulta, a fala reproduz exatamente o obervado. A grande maioria diz que a pós-consulta tem a finalidade de reforçar a orientação dada pelo médico quanto à medicação. Todas as categorias têm esta visão. A categoria profíssional que mais expressou preocupação com a má qualidade da pós-consulta foi a das enfermeiras, e isto é compreensível, uma vez que na formação desta profíssional enfatiza-se o papel educativo em saúde, principalmente as ações de prevenção e promoção da saúde.

Mesmo havendo um grupo de auxiliares e enfermeiras, que nas entrevistas expressou este direcionamento educativo das atividades de enfermagem, principalmente nas pós-consulta, isto não vem ocorrendo no trabalho. A pós-consulta tem a finalidade principal de decodificar a orientação médica, e esta "decodificação" se refere à medicação, não em função da sua ação terapêutica mas do modo de ministrá-la.

\subsection{Instrumentos de trabalho voltados para a saúde coletiva}

Neste movimento de caracterização dos momentos do processo de trabalho, introduzimos nas entrevistas questões referentes a alguns instrumentos voltados para a saúde coletiva, como as programações, o trabalho com grupos de cliente e/ou comunidades e a visitação domiciliar, além daqueles que serão analisados posteriormente, como a. vacinação e o sub-programa de suplementação alimentar.

Sobre a existência de programas implantados nas UBS, das 7 enfermeiras, 4 apontaram que existem e 3 que não existem conforme o preconizado. As primeiras fizeram referência ao programa de planejamento familiar, programa de suplementação alimentar, de pré-natal, da mulher, SISVAN, hipertensão arterial e diabetes.

Dos 10 médicos, 4 responderam que a UBS não desenvolve programas, 3 disseram que sim, fazendo referência ao planejamento familiar (2 deles) e um médico fez referência ao programa de hipertensão arterial e diabetes.

Das 17 auxiliares de enfermagem, 16 responderam que os programas existem e uma respondeu que não. Das 16 auxiliares de enfermagem que responderam positivamente, 10 fizeram referência ao programa de planejamento familiar e aleitamento (grupo de amamentação), 3 referiram à suplementação alimentar e as outras 3 ao programa de vacinação, ao de saúde da mulher e da criança.

A primeira análise que fazemos é sobre a concepção que os trabalhadores de saúde têm sobre 0 termo programa, concebendo algumas atividades como se fossem um programa em si mesmo. Entendem que o planejamento familiar É um programa, bem como o grupo de aleitamento materno. E mais, as auxiliares de enfermagem consideram a palestra de planejamento familiar como a parte central do programa de Saúde da Mulher. Parece que não concebem estas atividades como parte do programa de saúde da mulher e da criança.

A atividade educativa grupal é tomada na concepção da medicina preventiva individual. A concepção de programação como instrumento que objetiva a saúde coletiva não foi apontada. $E$ através da atividade educativa entendem que se está dando um atendimento de qualidade, pois o "paciente está sendo educado pelos profissionais da saúde", e assim "ele fica mais esclarecido".

Os programas são considerados como um instrumento em si mesmo sem remetê-los à finalidade maior da programação em saúde, tendo a epidemiologia como o saber que os instrumentaliza.

Os trabalhadores que fizeram referência à ação de um grupo apontaram as mesmas atividades destacadas anteriormente como programas de saúde.

Finalmente, quanto à visita domiciliária todos informaram que ela ocorre só em caráter eventual, de urgência e as visitas se referem geralmente ao controle da raiva, principalmente para aqueles que faltam ao esquema de vacinação, quando já iniciado.

$O$ raio de abrangência das UBS se restringe às atividades internas. Como a consulta médica do tipo pronto atendimento é a ação central,não se pode esperar que o raio de ação da UBS vá além das ações internas. Neste sentido as UBS têm uma ação bastante estática, são pouquíssimos os instrumentos voltados para a saúde coletiva. 


\section{A Suplementação Alimentar}

Os programas de Suplementação Alimentar são uma prática introduzida nos Programas Matemo-Infantis governamentais desde a década de 30 e 40.

Cada UBS utiliza uma forma de distribuição do leite, sendo que na maior parte das

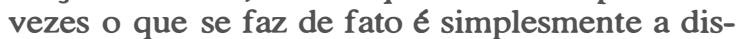
tribuição dos tíquetes, que é realizada da seguinte forma: pega-se as fichas de S.A. de todas as crianças que já estão presentes, anota-se o retorno e marca-se o leite fornecido e o próximo retorno, sem o controle de peso e estatura. A anotação da enfermagem feita no prontuário da criança (após terminar todos os atendimentos), à primeira análise pode parecer que contém os elementos essenciais para o acompanhamento do crescimento da criança ou seja, descreve as condições físicas aparentes da criança, o seu peso, os retornos e que a mãe encontra-se orientada; mas se não tivesse sido observado como este atendimento foi realizado, esta primeira análise permaneceria. Notou-se que o atendimento é rápido, pesa-se e mede-se as crianças sem verificar ganhos ou perdas, o diálogo com a mãe é lacônico, em cima das queixas, e não há $\mathrm{a}$ individualidade do atendimento.

É uma atividade bastante mecânica principalmente quando não se realiza o Atendimento de Enfermagem (o que ocorre em grande parte). O diálogo com os clientes é pobre e a relação/articulação com os outros setores quase não existe. A enfermeira é solicitada para casos com algum problema, como a mãe querendo receber leite e não está inscrita no progrạma. A articulação com o trabalho de pediatria se dá somente quando a criança é avaliada para ser inscrita no programa. $\mathrm{O}$ critério prioritário para a inclusão da criança no programa de suplementação alimentar é o risco de desnutrição. Juntamente com este, a todo instante, esbarra-se com famílias com "problemas sociais". Não há como separar desnutrição de condições sociais de vida.

A fala de alguns auxiliares mostra as ambiguiidades em que ficam os trabalhadores da saúde para desenvolver o programa de Suplementação Alimentar. Estas vão desde a compreensão de que somente é necessário distribuir (assistencialismo), de que não é preciso conscientizar o cliente porque este é muito ignorante, até o entendimento da função do Estado e as questões de condições de vida da população.

\section{A Vacinação}

As vacinas aplicadas de rotina nas UBS são aquelas do esquema infantil (Tríplice, Sabin, BCG-I.D, Contra Sarampo) e Dupla-Adulto para gestantes e em casos de ferimentos, e Con-
tra-Raiva, em acidentes com animais transmissores da raiva. Estas são aplicadas todos os dias, no período da manhã e da tarde, com exceção da vacina BCG-I-D., que é aplicada uma vez por semana ou a cada 15 dias de acordo com a demanda de crianças.

Nas três UBS o número de faltosos é grande. Em uma UBS não se convoca mais os faltosos (informaram que falta aerograma) e nas outras duas fazem a convocação por aerograma. Através do arquivo faz-se levantamento dos faltosos do mês anterior e mesmo após a convocação, o retorno não é de todos.

As três UBS informaram que não sabem qual o número da população infantil do bairro ou da área geográfica de abrangência da UBS. Desconhecem a sua cobertura vacinal e a porcentagem da sua população que procura a vacinação.

A vacinação é uma prática de saúde preventiva e coletiva e portanto necessita da identificação da população infantil (principalmente dos menores de 1 ano), para se programar a cobertura vacinal. Está sendo executada como se fosse um instrumento de alcance individual, ou seja, somente a criança que comparece é vacinada. Sabe-se que para erradicar determinadas doenças preveníveis por vacinação, não se pode atuar somente com aquelas que comparecem ao serviço, mas é preciso atingir a totalidade das crianças.

$O$ que se pode analisar são os dados das orientações feitas à mãe e/ou cliente no momento da aplicação e estas se referem às informações sobre a vacina aplicada (que tipo e sua finalidade), data de retorno e reação. Em relação à orientação sobre a vacina aplicada a frequiência das não orientações $\varepsilon$ grande, principalmente nas vacinas Tríplice, Sabin e Sarampo. As orientações mais corretas foram em relação ao BCG-I.D.

O setor de vacinação, nos serviços de saúde pública, sempre foi tomado, pela enfermeira, como mais de sua responsabilidade do que de outras categorias profissionais da saúde, pelo fato de estar sempre envolvida com as atividades do mesmo.

Um fator que atualmente coloca a vacinação em segundo plano é a crescente demanda da clientela por consulta médica, fazendo com que os recursos humanos de cada UBS, já em número reduzido, dêem cobertura às atividades advindas desta organização tecnológica do trabalho, a consulta médica.

\section{Coordenação/Supervisão/Controle do Trabalho}

Como já é de conhecimento que nas UBS é 
a enfermeira quem administra e executa o controle do processo de trabalho, as perguntas feitas a ela sobre este item foram em número maior que dos seus supervisionados (pessoal auxiliar). Em relação aos médicos as questões de Supervisão se restringem às relações do seu trabalho com a SMS e vice-versa, pelo fato de estes serem só consultantes.

As enfermeiras foram unânimes em dizer que quem responde pelas atividades da UBS são elas próprias. Deixaram transparecer que esta atividade de chefia é realizada de fato por elas na prática, mas não de direito, pois não se tem reconhecimento formal desta função pela SMS. A insatisfação com esta situação acentuou-se ainda mais na gestão atual da SMS e ainda após o aumento do salário do médico, ficando os outros trabalhadores de nível superior (que têm a mesma carga horária) com salário menor, como é o caso dos dentistas e enfermeiras.

Mas mesmo se pensando na construção de lugares sociais para as enfermeiras, neste processo de complementaridade do trabalho em saúde coletiva, o seu trabalho de coordenação/supervisão/controle tem se dado em função não do modelo epidemiológico, mas em função do modelo clínico.

Perguntamos às enfermeiras quais as atividades que supervisionam, e como se dá esta supervisão. Neste momento a representação das enfermeiras sobre a supervisão é tomada mais sobre a vertente de controle/fiscalização.

Em relação à ássessoria que a UBS recebe da SMS, esta foi identificada como eventual, somente quando solicitada, não havendo nada regularmente organizado nesta direção, mesmo ocasião de alguns treinamentos técnicos.

Ainda na caracterização do processo de supervisão as enfermeiras informam que o seu trabalho não é supervisionado. Há uma articulação com a divisão de enfermagem da SMS à distância, por telefone, ou por comunicados, e esta $\epsilon$ de acordo com problemas surgidos no dia a dia. Informam que o trabalho dos médicos é dos dentistas também não é supervisionado. Quanto ao trabalho dos auxiliares de enfermagem foram enfáticas em dizer, "aí sou eu quem faço a supervisão", mas acrescentam rapidamente, como que querendo amenizar o aspecto negativo do controle, "mas trabalhando junto com eles".

Quanto ao treinamento e reciclagem de todo o pessoal, as enfermeiras informaram que este é sempre assumido pela SMS de forma eventual. Quando se pretende introduzir alguma forma ou procedimento novo, ou um programa, um dos funcionários $\varepsilon$ indicado a participar, passando as informações para os outros.

Das 17 auxiliares entrevistadas e 3 escriturários todos reconhecem na enfermeira a figu- ra para quem se presta contas sobre o trabalho desenvolvido.

Quando perguntamos sobre as reuniões de serviço, a representação é a mesma das enfermeiras. Quando há uma norma ou procedimentos novos que serão introduzidos e nos casos de relacionamento, estas ocorrem de forma não rotineira.

Para a categoria dos médicos a questão da supervisão/controle se restringiu às informações sobre se "o seu trabalho é supervisionado, quais as relações de trabalho que mantém com a SMS e como se dá esta articulação e sobre as reuniões na UBS". Pelas falas, há um grupo que sente que deveria ter supervisão e outro que o trabalho do médico é autônomo, não há o que supervisionar. Esta representação deixa bem explícito o caráter autônomo que o médico dá para o seu trabalho (a consulta médica), se bem que admite o controle do trabalho em relação a horário.

Se não há uma decisão política do grupo no comando da SMS sobre a finalidade das UBS em função da organização tecnológica do trabalho no direcionamento da saúde coletiva, o que sobressai e acaba sendo cobrado dos trabalhadores $\epsilon$ de fato a produção em termos de quantidade, ou seja, quanto maior o número de pessoas atendidas, através da consulta médica, melhor está produzindo a UBS.

Com relação ao registro das atividades, tanto as enfermeiras quanto as auxiliares e os escriturários informaram que são estes dois que registram os dados das atividades desenvolvidas na UBS, sob a responsabilidade da enfermeira. Observou-se duas posições distintas quanto ao registro dos boletins e mapas de produção. Uma que o preenche por obrigação sem entender a sua razão e uma que dá aos mesmos o sentido de avaliação. Nos boletins e mapas de produção não há dados sobre a morbidade da demanda atendida, há a quantidade de clientes atendidos nas clínicas básicas.

Os médicos não registram e nem manipulam estes dados de produção. Como não há uma organização tecnológica do trabalho em termos de assistência médica em função de grupos de risco e nem em termos de cobertura de determinado percentual da população, não há consequientemente preocupação com a avaliação do trabalho, mesmo em termos quantitativos.

\section{A finalidade do trabalho e sua relação com as políticas de saúde}

Em relação à finalidade do trabalho em uma UBS, as respostas centraram-se em explicar se a UBS promovia a prevenção e/ou cura das doenças. Dos 37 trabalhadores, a grande maioria (25) considera que a UBS tem a finalidade de fazer a prevenção e cura das doenças. Esta representação ocorreu em todas as categorias profissio- 
nais.

Esta prevenção e cura são entendidas como: possibilitar atendimento médico para as pessoas que procuram assistência médica e orientá-las sobre a promoção e prevenção da doença em causa. Entende-se que procedimentos individuais, como cuidados higiênicos, regularidade nos comparecimentos médicos agendados, etc., levam à prevenção. Os que apontaram que não atingem as finalidades alegaram que é devido nao atender toda a demanda que procura os serviços e os que responderam que as UBS atingem apontaram que "os pacientes procuram o posto, são "atendidos e recuperam a saúde". Mais uma vez não se faz referência, ao atingir a finalidade, o fato de não se estar tomando a saúde enquanto objeto coletivo.

A doença-saúde é tomada não como um processo mas como se fosse possível separar nitidamente a prevenção da cura em se tratando do ponto de vista individual. Somente cinco trabalhadores ( 2 enfermeiras e 3 médicos) foram além do objeto indivíduo doente e fizeram alusão ao objeto coletivo, o corpo social.

As enfermeiras e médicos têm uma concepção homegênea frente às políticas de saúde: consideram que esta interfere diretamente no trabalho que as UBS realizam e no seu próprio trabalho. Julgam esta intếrferência negativa pois tomam as políticas como externas ao seu trabalho, arbitránias, feitas de cima para baixo, distantes da prática, realizadas por políticos e não técnicos, normativas, difíceis de serem viabilizadas,é como uma prática eleitoreira.

Em relação à representação das auxiliares de enfermagem e dos escriturários sobre as políticas' de saúde, há uma divisão em duas características, a primeira que é aquela semelhante a dos médicos e enfermeiras, como uma coisa externa, que é mal feita e não corresponde aos anseios da população e nem dos trabalhadores de saúde. A segunda é que as políticas não interferem no trabalho dos mesmos, pois não dependem dela. Entendem que a política é uma prática de favoritismo. Não deixa de ser tamberm uma visão de política como algo externo à sua prática.

Outra questão colocada foi a razão da esco- lha do trabalho na UBS (pergunta não feita para os médicos). A maior parte das enfermeiras e principalmente auxiliares de enfermagem, trabalha nas UBS por razão de ordem pessoal como: conciliar as atividades da casa, fazer pós-graduação, não dar plantōes e não trabalhar em final de semana.

De um modo geral pode-se concluir que não há uma opção pelo trabalho em saúde coletiva em função da sua finalidade específica. As conveniências pessoais e de facilidade foram as mais determinantes para o trabalho nas UBS. Desta forma fica mesmo distante o projeto social de transformar a saúde no sentido de sua maior democratização, uma vez que os próprios trabalhadores são despolitizados e sua prática é desenvolvida de forma imediatista com pouca reflexão.

\section{O Trabalho da Enfermeira}

As atividades da enfermeira foram classificadas em 5 grupos, dando a estes uma denominação bem próxima daquilo que foi realizado. A classificação foi a seguinte: GRUPO A - Procedimentos de enfermagem e comunicação com a clientela. GRUPO B - Comunicação e orientação dos trabalhadores de saúde e supervisão/controle do trabalho. GRUPO C - Manipulação de papéis e material. GRUPO D - Comunicação da UBS com Secretaria Municipal de Saúde e outros serviços e vice-versa. GRUPO E - Sem atividades.

De acordo com a Tabela 01, o tempo total de observação correspondeu a 1.440 minutos sendo que deste a maior parte, $39,2 \%$ correspondeu a procedimentos de enfermagem e comunicação com a clientela - Grupo A. A seguir, numa porcentagem de $23,1 \%$ estão distriburdas as atividades de comunicação e orientação dos trabalhadores de saude e supervisão/controle do trabalho - Grupo B. Em terceiro lugar a manipulação de papéis e material com $12,6 \%$ e em quarto as atividades de comunicação da UBS com Secretaria Municipal de Saúde e outros serviços e vice-versa, com 10,2\% - Grupo D. Há ainda uma última classifịcação que se refere a, Sem Atividades e que correspondeu a $14,8 \%$ de tempo - Grupo E. 
Tabela 01 - Distribuição das atividades da enfermeira, por minuto, as 3 UBS, em dois turnos de trabalho consecutivos.

\begin{tabular}{|c|c|c|c|c|c|c|c|c|}
\hline \multirow[t]{2}{*}{ A TIVIDADES } & \multicolumn{2}{|c|}{ UBS-A } & \multicolumn{2}{|c|}{ UBS-B } & \multicolumn{2}{|c|}{ UBS-C } & \multicolumn{2}{|c|}{ TOTAL } \\
\hline & Tempo & $\%$ & Tempo & \% & Tempo & \% & Tempo & $\%$ \\
\hline $\begin{array}{l}\text { A - Procedimentos de Enfermagem e } \\
\text { comunicação com a clientela }\end{array}$ & 216 & 45,0 & 148 & 30,8 & 201 & 41,9 & 565 & 39,2 \\
\hline $\begin{array}{l}\text { B - Comunicação e orientação dos } \\
\text { trabalhadores de saúde e }\end{array}$ & & & & & & & & \\
\hline & 68 & 14,2 & 112 & 23,4 & 152 & 31,7 & 332 & 23,1 \\
\hline $\begin{array}{l}\text { C - Manipulação de papéis e material } \\
\text { D - Comunicação da UBS com Secretari }\end{array}$ & 133 & 27,7 & 48 & 10,0 & - & - & 181 & 12,6 \\
\hline $\begin{array}{l}\text { Municipal de Saúde e outros serviços e } \\
\text { vice-versa }\end{array}$ & 59 & 12,3 & 76 & 15,8 & 14 & 2,9 & 149 & 10,3 \\
\hline E - Sem atividade & 04 & 0,8 & 96 & 20,0 & 113 & 23,5 & 213 & 14,8 \\
\hline Total & 480 & 100,0 & 480 & 100,0 & 480 & 100,0 & 1440 . & 000 \\
\hline
\end{tabular}

O que se pode observar é que nas UBS, de um modo geral, a enfermeira realiza procedimentos de enfermagem diretamente com a clientela, bem como atividades de comunicação e orientação dos trabalhadores de saúde, em sua grande maioria, os de enfermagem, e ainda executa aquelas atividades de organização do trabalho como manipulação de materiais e papéis, bem como de articulação do trabalho e deste com a SMS e outros serviços.

O que se observa neste trabalho é que nas UBS da SMS a enfermeira executa atividades de assistência de enfermagem em proporção um pouco maior que outros serviços. Atribuímos esta proporção maior de procedimentos de enfermagem realizados com e/ou para a clientela a duas razões. A primeira por se tratar de serviços de saúde em nível de atenção primária, como é o caso das UBS, possibilitando ao enfermeiro realizar além das atividades administrativas, procedimentos de enfermagem diretos com a clientela. A segunda razão se prende à organização tecnológica do trabalho que é centrada na consulta médica. Neste grupo as ações diretas são de dois tipos, aquelas que correspondem aos procedimentos técnicos de enfermagem como coleta de exames laboratoriais, vacinação e aplicação de tratamentos e aquelas de atendimento do cliente na recepção e triagem, encaminhamento e avaliação do estado de saúde do cliente. A enfermeira tem sido utilizada para fazer a triagem dos excedentes a fim de verificar aqueles que não podem ser dispensados e que caracterizam urgência e portanto precisam ser "encaixados" para a consulta médica, e aqueles que podem ser encaminhados para outros serviços ou dispensados para voltar em outra ocasião. As enfermeiras se consideram o "parachoque" desta demanda reprimida.

O segundo grupo de atividades realizadas pelas enfermeiras $(23,1 \%)$ que são as de comunicação, coordenação, controle e supervisão do trabalho e dos trabalhadores de saúde, está dividido em quatro blocos de atividades, ou seja, as conversas e diálogos informais com os trabalhadores sobre um setor e/ou serviço como um todo; as informações e orientações entre enfermeira e profissionais de nível superior; e o controle do próprio trabalho. Estes blocos correspondem, respectivamente, às porcentagens de: $27,1 \%, 28,8 \%, 19,8 \%$ e $24,3 \%$.

Este grupo de atividades que correspondem em ordem decrescente ao segundo tipo de atividades mais executadas pela enfermeira demonstra sua funçã̉o de coordenação, supervisão e controle das atividades que são executadas pelo pessoal auxiliar de enfermagem e de coordenação e articulação principalmente do trabalho médico com o trabalho de enfermagem. Demonstra também sua função de controle de todo o trabalho, ou seja controle de horários, férias de todos os trabalhadores, do trabalho desenvolvido pelas auxiliares de enfermagem, do ambiente de trabalho, de papéis, materiais, agendas médicas, prontuários e livros-registros.

Com relação ao terceiro grupo de atividades, a enfermeira na UBS é o elemento da equipe responsável pela previsão e requisição de todo o material utilizado, desde medicação, vacinas, até material de limpeza. Aqui estão agrupadas também as atividades de elaboração de escalas.

O quarto grupo de atividades é o de comunicação da UBS com SMS outros serviços e vice-versa. Aqui também houve uma subdivisão em três blocos, ou seja, comunicação através de telefonemas que correspondeu ao maior tempo gasto, seguida da comunicação por escrito e em último lugar através do motorista.

Finalmente o último grupo de atividades correspondeu a sem atividades que significa atividades de ordem particular, parada para café e sem executar atividade.

Nas falas sobre os procedimentos diretos com a clientela percebe-se que algumas enfermeiras valorizam as técnicas de enfermagem em si, e outras valorizam o trabalho educativo dos clientes, bem como a epidemiologia, apesar de 
que veêm enquanto ligada à vacinação. É importante ressaltar que as atividades de assistência de enfermagem diretas com a clientela correspondem à triagem, vacinação, marcação de consultas, encaminhamento e outras e não são realizadas de rotina; as enfermeiras fazem os atendimentos de urgência, os mais complexos e também há a falta do funcionário.

Outra discussão importante para ser trazida e que vai caracterizar o modelo de organização tecnológica do trabalho nas UBS é a natureza das atividades. Tanto as de ordem administrativa bem como as de ordem assistencial não revelam em nenhum momento tecnologia programáticas em saúde, revelam pelo contrário, o pólo oposto, assistência médica individual enquanto modelo hegemônico.

As poucas ações de enfermagem, como educação em saúde, visitas domiciliares e trabalhos de grupos que se caracterizam como algumas das atividades mais voltadas para a saúde coletiva, na realidade não estão cumprindo esta finalidade, pois são realizadas isoladamente e de forma a atender às necesidades individuais e imediatas.

Como nas UBS a organização tecnológica do trabalho está direcionado para o modelo clínico de saúde, as ações de enfermagem, como parte deste trabalho, que têm um único objeto. que é o corpo anátomo-funcional, são auxiliares do trabalho médico, são ações muito pobres. Se 'fosse o modelo sanitário em vigência, que tem como objeto o fenômeno coletivo do processo saúde-doença, a ação de enfermagem seria de complementariedade para a saúde coletiva e não uma ação exclusivamente auxiliar.

\section{CONCLUSÕES}

Retornando à trajetória deste trabalho, o mesmo tinha como objetivo caracterizar o trabalho de enfermagem na rede básica de serviços públicos de saúde de Ribeirão Preto e, nesta identificação da organização tecnológica do trabalho que aí se dá, analisar como a enfermagem, por ser uma ação parcelar do trabalho na saúde, se articula, técnica e socialmente neste processo de trabalho e à que finalidade responde.

Através das técnicas de pesquisa-observação direta e entrevistas - trabalhando e analisando cada setor e/ou ação do trabalho, de per si, e a relação entre os mesmos, foi possível fazer esta identificação e no mesmo processo apontar os nexos e os desdobramentos do esquema operativo em saúde assumido pelas Unidades Básicas de Saúde de Ribeirão Preto.

Assim a organização tecnológica do trabalho em saúde nas UBS pode ser identificada como o Novo Modelo Assistencial, que substituiu, no Estado de São Paulo, o Modelo Pro- gramático. A característica central do Nove Modelo Assistencial é o Pronto-Atendimento, que tem como ação nuclear a consulta médica. Esta não se fundamenta na história clínica dos clientes, mas sim no problema e na queixa apresentada. O seguimento clínico e o acompanhamento do cliente não são necessários, pois o modelo é o pronto-atendimento.

Como o trabalho na saúde é coletivo e cada trabalhador ou cada ação são parcelares, e como o núcleo do modelo é a consulta médica do tipo pronto-atendimento, os outros trabalhos que aí são operados têm a finalidade de auxiliar as ações médicas, ou seja, completar o ProntoAtendimento. Portanto o trabalho de enfermagem se caracteriza como um trabalho auxiliar das atividades do pronto-atendimento. Assim a recepção do cliente tem a função principal de controlar a demanda espontânea, que é sempre maior que a possível de ser atendida. A préconsulta tem a finalidade de pesar e medir os clientes nara possibilitar ao médico fazer as prescriçóes medicamentosas: A pos-consulta tem a finalidade de orientar os clientes sobre a ministração das medicações.

Identificou-se que este bloco de ações (recepção da clientela, pré-consulta, consulta médica e pós-consulta) é o trabalho das UBS. Este é realizado de forma rápida, confusa, com diálogos monossilábicos e truncados e tem um nivel de tensão e insatisfação considerável, pelo lado dos trabalhadores. Estes setores se articulam no limite exato das necessidades do pronto-atendimento. Deste bloco de ações se desdobram outras atividades auxiliares, ou se ja, coleta de exames laboratoriais, curativos, aplicação de tratamento como injeções, aerosóis, testes alérgicos, orientações sobre as prescrições e encaminhamentos a serviço de nível secundário. Portanto o corpo anátomo-patológico na sua expressão (aparência) de "queixas e problemas" é o objeto de trabalho médico e de todos os outros trabalhos da UBS.

As outras ações que seriam instrumentos de trabalho para alcançar a saúde coletiva, como visitas domiciliares, trabalhos educativos, atividades externas com grupos populacionais ou em instituições, vigilância sanitária e epidemiológica, não são realizadas pelas UBS, com poucas exceções.

A suplementação alimentar não tem articulação com a pediatria, é um trabalho que se caracteriza mais como distribuição de lẹite sem o acompanhamento do crescimento e desenvolvimento infantil e sem ações educativas.

A vacinação infantil, que é uma ação que visa o controle de doenças transmissíveis da população de crianças, é realizada visando a prevenção individual e de certa forma como medida de controle social dos clientes.

Os momentos deste processo de trabalho 
ou seja, objeto, instrumentos e produtos são guiados pela intencionalidade, que é a atividade orientada para um fim. E esta finalidade que está guiando este processo de trabalho, é a consulta médica na modalidade de Pronto-Atendimento, que se consome no limite do corpo biológico e mais, na "queixa" que é identificada.

A concepção dos trabalhadores sobre o seu trabalho tem uma representação do imediatismo da sua prática. $O$ trabalho é tomado como uma ação técnico-científica que deixa de ter altos índices de resolutividade porque a clientela é considerada como "pobre, ignorante, sem elementos para absorver, aproveitar e consumir com resolutividade os serviços prestados". Nesta mesma direção as políticas de saúde são vistas como externas ao trabalho e ao trabalhador, como instância que só "maculam" as boas intenções dos técnicos.

O projeto de Saúde Coletiva fica mais distante ainda dos trabalhadores da saúde, como se não fosse tarefa também dos mesmos para ser refletido e realizado, também no cotidiano trabalho da saúde.

O Pronto-Atendimento que vem ocorrendo no processo de municipalização da saúde não é o resultado exclusivo da decisão dos trabalha- dores da saúde, tem que ser entendido nas contraditórias relações ' sociaıs, da ' conjuntura econômica-política e social do país. Assim, nos primeiros anos da década de 80 temos a população (principalmente não previdenciária) necessitando de assistência médica e reinvidicando este atendimento. Por outro lado a Previdência Social passando por sua maior crise financeira e propondo as AIS, para a integração institucional dos serviços e o repasse de verbas do atendimento ambulatorial da rede privada conveniada para o estado e município. Acresce-se a força hegemônica do modelo clínico e o fortalecimento da política neo-liberal no cenário econômico-social brasileiro. Esta conjuntura encaminha o setor saúde, principalmente o nível de atenção primária para a resolutividade da porta de entrada do sistema. Isto comandou a ampliação e diversificação da assistência médica individual, ou seja, as portas foram abertas para "toda a população" e as Unidades passaram a ser equipadas com medicamentos e instrumental antes inexistentes como ultra-sonografia, Raio X, exames laboratoriais e outros serviços especializados. A assistência médica individual que era um dos instrumentos para alcançar a saúde coletiva, passou a ser a finalidade central da rede básica dos serviços de saúde.

\section{REFERÊNCIAS BIBLIOGRÁFICAS}

1 ASSOCIAÇĀO PAULISTA DE SAÚdE PÚBLICA. 1 Encontro Estadual sobre Planejamento e Ação Programática em Saúde - Relatório Final. São Paulo, 6-8 jan, 1990.

2 CAS TELLANOS, B.E.P. et alii. Os desafios da enfermagem para os anos 90. In: CONGRESSO BRASILEIRO DE ENFERMAGEM, 41, Florianópolis, 2-7 set. 1989. Anais. Associação Brasileira de Enfermagem, 1989, p. 147-169.

3 MENDES-GONÇALVES, R.B. Tecnologia e organização social das práticas de saúde: características tecnológicas do processo de trabalho na rede estadual de centros de saúde de São Paulo. São Paulo, 1986. 416 p. Tese (Doutorado). Faculdade de Medicina da Universidade de São Paulo. Departamento de Medicina Preventiva.
4 O processo de trabalho em saúde. São Paulo, Departamento de Medicina Preventiva da Faculdade de Medicina da USP, 1988 (mimeogr.) 31 p.

5 NEMES, M.I.B. Ação programática em saúde: recuperação histórica de uma poltica de programação. In SCHRAIBER, L.B. (org.) Programação em Saúde hoje. São Paulo: Hucitec, 1990, p. 65-116.

6 SCHRAIBER, L.B. Programação em saúde hoje. São Paulo: Hucitec, 1990. 226 p。

7 SECRETARIA MUNICIPAL DE SAÚDE DE RIBEIRĀO PRE TO. Plano Diretor de Saúde do Município de Ribeirão Preto. Comissão Interinstitucional Municipal de Saúde. 15/05/1990. 